\title{
QUEM SEMPRE ESPERA POR VOCÊ? UMA CAMPANHA DO MCDONALD'S PARA O MCLANCHE FELIZ
}

\author{
Cristhiane Ferreguett ${ }^{1}$ \\ Paulo Henrique Bonfim Scheidegger ${ }^{2}$
}

\begin{abstract}
Resumo: A partir do dispositivo teórico da Análise de Discurso, linha francesa, analisa-se os discursos publicitários divulgados na campanha do McLanche Feliz, lanche especial para crianças, da rede de fast-foods Mc'Donald's. O corpus desse artigo foi coletado no canal McDonald's Brasil, via plataforma Youtube, trata-se de um vídeo elaborado para a campanha/2019 intitulado Quem sempre espera por você? cujos protagonistas são os personagens do filme Pets2: a vida secreta dos bichos, produzido pela Universal Studios. O enunciador propõe, através da memória discursiva, que os pets estão sempre à espera de seus tutores e os cãezinhos são associados, através dos brindes, ao McLanche Feliz. Isso facilita a adesão da criança ao discurso que está sendo apresentado e um possível consumo e fidelização ao produto.
\end{abstract}

Palavras-chave: McDonald's; Publicidade infantil; Análise de Discurso; McLanche Feliz.

\section{Introdução}

Este trabalho analisa os discursos publicitários divulgados na campanha - em forma de vídeo - para o serviço McLanche Feliz, especial para crianças, da rede de fast-foods Mc'Donald's. O corpus desse artigo foi coletado no canal McDonald's Brasil, via plataforma Youtube, trata-se de um vídeo elaborado para a campanha/2019 intitulado Quem sempre espera por você? cujos protagonistas são os personagens do filme Pets: a vida secreta dos bichos 2, produzido pela Universal Studios.

O trabalho está ancorado na teoria da Análise de Discurso, linha francesa, de Michel Pêcheux. Objetiva-se, identificar as condições de produção do discurso - sujeito, situação e memória - observadas ao longo da peça publicitária e a possível influência que esses mecanismos podem exercer na decisão da criança (ou responsáveis) pela compra do produto McLanche feliz.

\footnotetext{
${ }^{1}$ Professora Adjunta da Universidade do Estado da Bahia - UNEB; Doutora em Letras (PUCRS); Mestre em Estudos de Linguagens (UNEB).

${ }^{2}$ Graduando do curso de licenciatura em Letras, Língua Inglesa e Literaturas pela UNEB, Campus X.
} 
O desenvolvimento está dividido em duas sessões, a primeira intitulada $A$ influência do discurso publicitário sobre a criança apresenta revisões bibliográficas sobre o discurso publicitário e sua influência para a formação de crianças consumidoras. A seção a seguir, cujo título é Quem sempre espera por você? Análise de uma campanha do McLanche Feliz, apresenta um olhar da teoria da Análise de Discurso (AD) sobre os elementos de linguagens e imagens ${ }^{3}$ apresentadas no filme promocional do McDonald's. O embasamento da teoria que norteia nosso trabalho é apresentado de forma integrada às análises e a partir dessas, concluímos o artigo.

\section{A influência do discurso publicitário sobre a criança}

A psicóloga norte-americana Susan Linn (2006) acredita que as crianças são mais vulneráveis ao marketing do que os adultos. Ela afirma que as crianças em idade pré-escolar, por exemplo, têm dificuldade em diferenciar comerciais de programas normais de televisão. Linn (2006, p. 22) constatou, através de pesquisas, que até a idade de oito anos "as crianças não conseguem realmente entender o conceito de intenção persuasiva - segundo o qual cada detalhe de uma propaganda foi escolhido para tornar o produto mais atraente”. Para essa autora, crianças mais velhas e adolescentes podem ser mais críticas em relação à propaganda, mas seu senso parece não afetar a tendência de querer ou comprar produtos apresentados pela publicidade. De acordo com Linn (2006, p. 23), "a propaganda agrada às emoções e não ao intelecto, e afeta as crianças ainda mais profundamente do que os adultos”. Ela alerta que a explosão de marketing voltado para as crianças hoje é "direcionada de maneira precisa, refinada por métodos científicos e lapidada por psicólogos infantis - resumindo, é mais penetrante e importante do que nunca" (LINN, 2006, p. 25).

Veloso et al. (2012) também discutem sobre a percepção da propaganda por parte da criança. Afirmam que pesquisadores norte-americanos, através de técnicas de observação, constataram que crianças de até seis anos de idade não percebem claramente quando começam os comerciais televisivos e continuam prestando atenção na televisão, mas crianças entre seis a oito anos compreendem a diferença entre um comercial e a programação normal da televisão.

Para Veloso et al. (2012, p. 142), a diferenciação entre o que é e o que não é propaganda pode se tornar ainda mais complexa diante das "inovações realizadas pelos profissionais de marketing”. A inserção das ações promocionais dentro de uma programação normal faz com que a separação entre o que é propaganda e o que não é se torne ainda mais difusa. Isso acontece quando, por exemplo, o próprio apresentador do programa de TV anuncia um produto. Outro exemplo citado são os sites que procuram vender a marca e os produtos de uma empresa entre jogos e brincadeiras ou os brindes oferecidos com marcas e personagens

\footnotetext{
${ }_{3}^{3}$ Screenshots feitos das imagens do filme promocional
} 
estampados, “de qualquer forma, a crescente sofisticação das ações de marketing caminha para tornar os limites entre propaganda e o conteúdo mais nebulosos" (VELOSO et al., 2012, p. 142).

Ao longo dos anos, a criança, exposta à propaganda, vai desenvolvendo uma série de estratégias para solicitar aos pais o produto ou serviço que quer. A partir de 2004, o canal infantil de TV por assinatura Cartoon Network passou a realizar estudos anuais para conhecer melhor o seu público - crianças e adolescentes das classes A e B. A pesquisa recebeu o nome de Kids Expert. A versão de 2007 - realizada em São Paulo com mais de mil pessoas com idades entre sete e quinze anos - foi disponibilizada na biblioteca virtual do Instituto Alana. Para a pergunta ${ }^{4}$ "quando você quer alguma comida, roupa, tênis ou brinquedo, de que modo você pede isso para seus pais?", as respostas mais repetidas pelos entrevistados foram: "prometo tirar boas notas na escola"; "falo que está barato e explico o que tem de bom” (KIDS EXPERT, 2012, p. 11).

Para os profissionais do Mundo do Marketing, ${ }^{5}$ revista na internet especializada em propaganda, as modificações sociais e as organizações familiares refletiram diretamente no modelo educacional dos filhos. Pelo fato de não poder mais acompanhar de perto o desenvolvimento das crianças, os pais passaram a permitir e até mesmo a encorajá-las na participação da tomada de decisão dentro de casa. Os especialistas acreditam que a tendência é que cada vez mais a relação seja marcada pela negociação e pelo diálogo, pois os pequenos passaram a ser ouvidos e ter direito a fazer reivindicações.

Os especialistas em marketing festejam essas mudanças, uma vez que eles têm a certeza de que as crianças desempenham hoje um papel importante no ato de consumir. A facilidade de acesso à informação também contribui para essa mudança de comportamento. As crianças têm quartos equipados com computadores com acesso à internet, televisões, rádios e/ou telefones. Na pesquisa Kids Expert - versão de 2007, para a pergunta que questionava o presente favorito os itens dinheiro, eletrônicos (MP3, MP4, Ipod) e videogames foram os que tiveram maior percentual de respostas. Esse acesso permite que informações sobre produtos e marcas cheguem rápida e facilmente e faz com que elas sejam, muitas vezes, mais conhecedoras das ofertas do mercado do que seus próprios pais:

Mais informado, o público infantil se torna três em um: exercem o papel de consumidores mirins; são promotores do consumo familiar; e serão adultos consumidores. Com opiniões formadas e vontade própria, as crianças são um alvo apetecível para o mercado. As estratégias de Marketing devem ser definidas a curto, médio e longo prazo, o que implica dizer que as marcas têm que pensar o que farão hoje para receber os frutos desse planejamento num prazo de cinco a dez anos. Conquistar as crianças,

\footnotetext{
${ }^{4} \mathrm{O}$ estudo não esclarece se as perguntas eram seguidas de respostas objetivas para escolha ou se era dado um espaço para uma resposta subjetiva.

${ }^{5}$ Disponível em: https://www.mundodomarketing.com.br/. Acesso em: 25 nov. 2019.
} 
no entanto, é tarefa árdua. Apesar de inocentes, são também muito voláteis e exigentes, sendo difícil fidelizá-las. (LEITTE, 2013, p. 3).

A revista eletrônica Mundo do Marketing aponta que é difícil encontrar um ponto de aderência para que as crianças se aproximem e criem vínculos. Ressalta que as empresas precisam compreender que o público infantil nasceu em plena era tecnológica e alertam que uma estratégia errada pode afetar o diálogo e a fidelização. O Mundo do Marketing reproduziu informações parciais de um estudo realizado em 2012, denominado Infância Influente, pelo TNS Global/InterScience, um instituto de pesquisa que atua em mais de 70 países. Segundo o estudo, com foco em crianças de seis a onze anos, o objetivo das empresas tem de ser na geração de experiências para criação de vínculos afetivos. No entender deles, ainda que as crianças não entendam as mensagens com a mesma propriedade que os adultos, podem referenciar as marcas por meio de seriados, personagens e ídolos.

A pesquisa realizada pelo TNS Global/InterScience ${ }^{6}$ aponta para cinco tendências do mercado. A primeira delas é a compreensão que os pequenos têm da tecnologia; segundo ponto é que as empresas precisam entender que as crianças não atuam apenas como receptores de informação, mas também como emissores. Outro ponto é a autossuficiência, quando as crianças buscam informações elas devem estar disponíveis onde, como e quando querem. Há outro estudo realizado em 2012 pelo Q Painel Kids \& Teen, do instituto Qualibest, que indica a forte presença da tecnologia na vida de crianças de 8 a 12 anos. Todas as crianças entrevistadas têm pelo menos um item eletrônico, seja de uso exclusivo ou compartilhado. Enquanto computadores e laptops ainda são de uso dividido com outras pessoas da casa (67\% e $46 \%$, respectivamente), os celulares já se tornam itens individuais - 57\% têm seu próprio aparelho e apenas $21 \%$ compartilham o aparelho com outro usuário (MUNDO DO MARKETING, 2013).

Outro dado - apresentado pelo Mundo do Marketing - é que a criança brasileira - avaliada pelo Ibope Nielsen Online - é a que fica mais tempo em frente ao computador conectada à internet em todo o mundo. A pesquisa de consumo infantil Kids Expert 2008, realizada pelo canal de TV Cartoon Network com mais de sete mil pessoas na faixa de sete a quinze anos, concluiu que a partir dos seis anos as crianças são introduzidas a aparelhos tecnológicos além da TV, e aos nove anos já utilizam computadores, internet e videogames, para, em seguida, interagirem com comunicadores ( $M S N$, mensagens de textos, blogs) e celulares. Entre os doze e dezesseis anos, os jovens também deixam a passividade e começam uma busca incessante por informação, além de dominarem totalmente os artefatos tecnológicos a que têm acesso.

Veloso et al. (2012, p. 119) recomendam que "as empresas também devem se preocupar em desenvolver marcas e símbolos que sejam facilmente lembrados e

\footnotetext{
${ }^{6}$ Esta pesquisa foi reproduzida em partes no estudo do Mundo do Marketing restrito aos assinantes intitulado Quem é o consumidor infantil. Disponível em: http://www.mundodomarketing.com.br/mais-mundo-do-marketing/estudos/12/quem-e-o-consumidor-infantil-.html. Acesso em: 25 nov. 2013.
} 
reconhecidos pelas crianças”. Os autores afirmam que, ao utilizar uma personagem famosa e aceita em um determinado grupo de crianças, a empresa que adquire essa licença está comprando automaticamente "certo nível de aceitação nesse grupo” (VELOSO et al., 2012, p. 121). Para Veloso et al. (2012), os custos associados ao licenciamento são menores do que o custo necessário para construir uma demanda para um produto com marca desconhecida das crianças. Esses autores afirmam que os personagens fazem parte do imaginário das crianças, e que marca e personagem se tornam uma representação viva da marca junto às crianças, uma vez que elas se relacionam ou se identificam com as personagens.

Linn (2006), enquanto defensora da criança consumidora, alerta que por meio de endossos e acordos de licenças, personagens de desenhos animados, cantores pop, ídolos do esporte e astros do cinema são hoje ícones de junkfood, brinquedos, roupas e todo acessório que se possa imaginar. Observamos que a realidade no Brasil não é diferente da realidade dos Estados Unidos, descrita por Linn (2006). O estudo Kids Expert 2007, realizado em São Paulo, apresentava no rol das perguntas, inclusive, uma que questionava “quem você gostaria de ser?” (KIDS EXPERT, 2012, p. 5). As respostas foram organizadas em um gráfico que diferencia as respostas das meninas e as dos meninos através das cores rosa e azul, respectivamente. Enquanto os meninos centralizaram suas respostas em duas opções, as meninas se dividiram entre várias alternativas: $47 \%$ dos meninos responderam que gostariam de ser um personagem de desenho animado e $21 \%$ responderam um atleta. As meninas se dividiram entre diversas opções, sendo as mais votadas: um ator/ atriz (24\%), um cantor/músico (23\%), um personagem de desenho animado (18\%), um/uma modelo (16\%) (KIDS EXPERT, 2012, p. 5).

O Mundo do Marketing ressalta ainda a importância do licenciamento. Segundo esse site, a relação das crianças com o consumo e com as marcas mudou: mais do que influentes, elas são decisórias. De acordo com a pesquisa, já mencionada, $30 \%$ das crianças vão de forma rotineira aos supermercados com seus pais, que mudaram os hábitos de compras mensais e passaram a frequentar os locais semanalmente (MUNDO DO MARKETING, 2012). Com ou sem pressão, eles acabam cedendo, na maioria das vezes.

Segundo o Mundo do Marketing, para conquistar as crianças é fundamental o uso do licenciamento de personagens, filmes ou desenhos em diversas categorias. Na cabeça dos pequenos o produto sempre está associado a um personagem. Além disso, os próprios pais criam uma relação afetiva ao levar algo com o desenho de que o filho ou a filha gosta:

Do banheiro ao lanche da escola, passando pelas roupas que os pequenos usam, as marcas estão inseridas na vida das crianças e elas, por sua vez, as mencionam diariamente. Segundo a pesquisa, porém, não basta apostar na visibilidade garantida por marcas e personagens famosos. 'Do ponto de vista de posicionamento, fica mais fácil para as companhias falarem de atributos de seus produtos tendo a Pucca ou o Homem Aranha' [...]. 
O destaque nessa relação é que ao terem opções variadas em categorias diversas, as crianças dialogam com as marcas e, em seguida, com seus pais. 'Elas pensam que se existe um produto com esses desenhos, logo em seguida existirão comerciais deles. Assim, elas poderão pedir para os pais, que reconhecerão mais facilmente nas lojas, gôndolas ou farmácias o que elas querem. É um ciclo e as crianças convivem desde muito pequenas com personagens diversos que fazem parte da rotina delas'. (NICOLINO, 2013, p. 01). ${ }^{7}$

Além do licenciamento, outra técnica utilizada é a exposição de produto ou merchandising e inclusão de propaganda de produtos em pontos de encontro, cenários e acessórios dentro de filmes e programas televisivos. Linn (2006) alerta que, como se não bastasse, ainda existem brinquedos para estimular o consumo:

O consumismo como valor é anunciado em forma de brinquedos. Para as festas de 2003, a Mattel produziu pelo menos sete conjuntos da Barbie envolvendo temas relacionados a compras. Além da Barbie Vai às compras, havia Barbie na Loja de Brinquedos, Barbie Comprando Doces, Barbie Compras Fashion, Barbie no salão de Beleza, Barbie na Loja de Calçados e Barbie na Loja de Donuts. (LINN, 2006, p. 29).

O estudo do painel QPainel Kids \& Teen, apresentado em outubro de 2012 pelo Instituto Qualibest, identificou de forma qualitativa e quantitativa como os consumidores de 8 a 12 anos se portam na hora de se relacionar com as marcas. A pesquisa indica que crianças ainda não têm a consciência plena de que forma devem consumir e como podem economizar. As crianças sabem que não podem comprar sozinhas e por isso mesmo pedem muito aos pais, mas não conseguem deliberar se aquilo que pedem é necessário ou supérfluo para suas vidas. As pesquisas indicam os pontos de fragilidade das crianças e de seus pais, e é nesse ponto poroso que a publicidade pretende se inserir. Para Linn (2006), a longo prazo essa imersão das crianças na cultura comercial traz consequências que vão muito além do que eles compram ou não. O marketing é formulado para influenciar mais do que preferências por comida ou escolhas de roupas, "ele procura afetar os valores essenciais como as escolhas de vida: como definimos a felicidade e como medimos nosso valor próprio" (LINN, 2006, p. 29).

De acordo a Linn (2006), as agências de marketing buscam conhecimento a respeito da criança como uma instituição acadêmica, porém com mais recursos que a maioria das universidades. Outra questão que diferencia a pesquisa realizada pelos dois grupos é o fato de que as pesquisas acadêmicas são regulamentadas por comissões éticas, e a pesquisa de mercado não está sujeita a nenhuma regulamentação. Ela brinca com essa realidade com o seguinte comentário: "imagine que um pesquisador se aproxime de você e diga: 'estou conduzindo uma pesquisa cujos

${ }^{7}$ Luisa Nicolino, diretora de marketing e inovação do Instituto QualiBest, em entrevista ao Mundo do Marketing. 
resultados tornarão sua vida mais estressante, pois seus filhos terão mais habilidades de importuná-los a fim de comprar coisas’. Você participaria?” (LINN, 2006, p. 61).

Veloso et al. (2012, p. 158) também abordam a questão da pesquisa e alertam os profissionais do marketing para a importância desse mecanismo para testar comerciais antes da sua "custosa circulação nos diferentes tipos de mídia”. Ressaltam ainda a necessidade de as empresas de marketing testarem o "impacto do produto e do comercial no seu todo” (VELOSO et al., 2012, p. 158), não esquecendo nenhum detalhe (letra e texto, cores, sons etc.).

Para Linn (2006), enquanto os pais estão tentando estabelecer limites, o marketing trabalha dia e noite para minar essa autoridade:

\begin{abstract}
Quando se trata de aliviar os danos causados pela publicidade às crianças, a solução mais fácil é culpar os pais. É o que a indústria adora fazer. No entanto, como pode uma família, sozinha, proteger seus filhos de uma indústria que gasta US $\$ 15$ bilhões de dólares anualmente para manipulá-los? É uma luta mais difícil porque uma das técnicas primárias que os profissionais de marketing usam para manipular as crianças é denegrir e enfraquecer a autoridade dos pais (LINN, 2006, p. 243).
\end{abstract}

Outra estratégia utilizada pelo mundo publicitário é a lealdade à marca; segundo especialistas, marcas que foram emblemáticas na infância geralmente conquistam a lealdade de um púbico por toda a sua vida. Linn (2006, p. 238) cita o publicitário James Mc Neal, que discorre sobre esta questão: “temos provas vivas da qualidade duradoura de lealdade precoce à marca no marketing do berço ao túmulo como o McDonald's, e como funcionam bem"; segue a descrição da estratégia: "começamos a levar as crianças lá para o primeiro e segundo aniversário e assim por diante. [...]. As crianças carregam isso com elas durante toda a vida.” Segundo Linn (2006), conforme a lealdade a uma marca cresce, menos sensíveis ficam os clientes às mudanças de seus preços.

$\mathrm{O}$ apelo emocional que estimula compras feitas sem qualquer tipo de análise racional também é considerado como uma estratégia publicitária. Conforme Linn (2006), a maioria dos comerciais para as crianças contêm pouca informação útil sobre os produtos; em alguns casos não contém informação nenhuma. Veremos como isso acontece na prática, na próxima sessão dedicada a análise do nosso corpus, o vídeo publicitário da McDonald's para o McLanche Feliz.

\title{
3 Quem sempre espera por você? Análise de uma campanha do McLanche Feliz
}

A publicidade do Mclanche Feliz, da rede de fast food McDonald's, é dedicada ao lanche elaborado especialmente para o público infantil. Este lanche sempre vem acompanhado de um brinde para as crianças, a oferta é um artifício para seduzir as crianças que frequentam a rede McDonald's. Os brinquedos oferecidos 
são exclusivos e mudam em cada campanha, geralmente reproduzindo personagens de desenhos e filmes infantis, acompanhando a tendência do momento no mundo das crianças.

Nosso corpus é o filme publicitário lançado no ano de 2019, fruto de uma parceria feita entre a rede de fast-foods, McDonald's, e a distribuidora do filme Pets 2: a vida secreta dos bichos, a Universal Studios, o resultado desse casamento é o lançamento de uma nova campanha do McLanche Feliz intitulada Quem sempre espera por você?

Figura 1: Capa da campanha

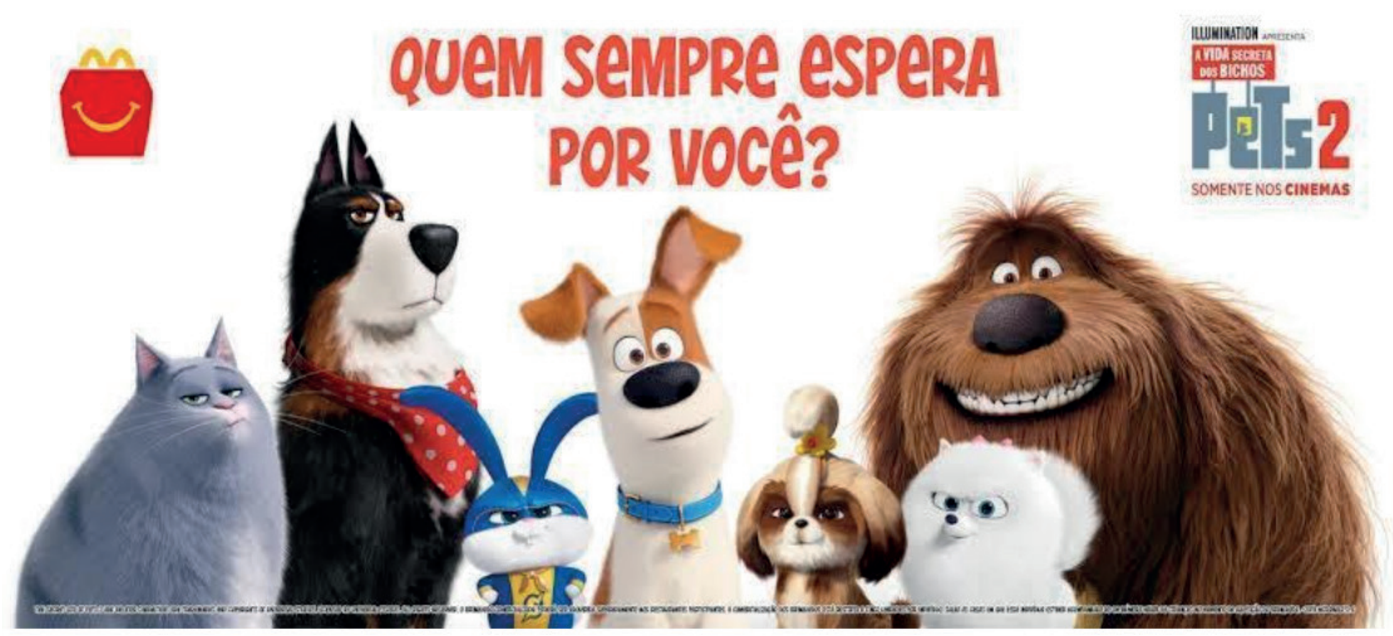

Fonte: McDonald's Brasil (2019)

A campanha foi exibida na plataforma Youtube da McDonald's Brasil ${ }^{8}$, os brindes dessa campanha são miniaturas dos personagens do filme Pets 2: a vida secreta dos bichos, uma animação da Universal Pictures, estilo comédia, dedicada ao público infanto-juvenil. Os personagens principais são dois cães Max e Duke, dois cativantes cãezinhos, que precisam se adaptar à chegada de Liam, o novo bebê da família.

Como já foi dito na introdução, o aporte teórico para a análise do corpus selecionado é a Análise do Discurso, linha francesa. Para Pêcheux (2015, p. 19), o corpus é definido como "os escritos, as imagens, os ditos, as novas tecnologias, fotos, o silêncio e muitos outros, cada qual com suas especificidades, seus dispositivos analíticos e sua contribuição para a compreensão dos processos de significação”. Desta forma, considera-se relevante para análise as imagens exibidas no vídeo, os silêncios, os sons, as cores e os enunciados verbais.

A Análise de Discurso (doravante $\mathrm{AD}$ ) é um campo teórico da linguística na área da comunicação, que consiste em analisar a estrutura de um texto e a partir disto compreender as construções ideológicas presentes no mesmo, e foi inaugurada no final da década de 1960, pelo filósofo Michel Pêcheux. A teoria se fundamenta sob três suportes teóricos: Saussure, Marx e Freud:

$\overline{8}$ https://www.youtube.com/watch?v=ZkxIVFaTD1g $\& a b$ _channel=McDonald\%27sBrasil 
Na linguística, com a problematização do corte saussureano, dando a Saussure o lugar de fundador da linguística como ciência e retomando a sua idéia de "real da língua" na noção de sistema; mas ao mesmo tempo, centralizando a análise semântica, com a ideia da não-transparência do sentido, da não-reflexividade entre signo/mundo/homem. No materialismo Histórico, por meio da releitura althusseriana de Marx, com a ideia de que há um real da história que não é transparente para o sujeito, pois ele é assujeitado pela ideologia. Na psicanálise, por meio da releitura lacaniana de Freud, com a ideia do sujeito na sua relação com o simbólico, pensando o inconsciente como estruturado por uma linguagem. (GREGOLIN, 2001, p. 03).

A AD concebida por Pêcheux não trabalha com o discurso empírico de um sujeito, nem com o texto, mas com o processo, ou melhor, com o discurso como processo, questionando sobre as condições de produção (sujeito, situação e memória) que também o constitui para apreender os diversos sentidos da leitura o analista trabalha com as condições de produção. Para Maldidier (2003, p. 23) "a referência às condições de produção designava a concepção central do discurso determinado por um 'exterior' como dizia então, para evocar tudo, o que, fora a linguagem, faz com que um discurso seja o que é: o tecido histórico-social que o constitui”. Orlandi (2000, p. 30-31) esclarece que os sujeitos e a situação, acionados pela memória, constituem as condições de produção.

Voltando para o filme publicitário, observa-se que ele possui apenas trinta segundos de duração, e apesar de ser curto, o tempo é suficiente para cumprir sua função de propaganda, trabalha no patamar do devaneio, empregando fantasias, retratando pessoas belas, felizes e realizadas. Os primeiros nove segundos do vídeo são marcados pela trilha sonora da música "Right here waiting", do cantor americano Richard Marx. As sentenças cantadas são os três primeiros versos do refrão da música que dizem: "Wherever you go / Wherever you do / I will be right here waiting for you". ${ }^{9}$

Apesar de a propaganda ser veiculada em território brasileiro, o marketing do McLanche feliz não parece se preocupar com a tradução da música, mantendo-a em sua versão original. Uma possível interpretação dessa escolha é que, tendo em vista o público alvo da campanha e sua baixa capacidade de concentração, manter a trilha sonora em língua estrangeira, mesmo no Brasil, pode ser entendido como uma estratégia de fazer com que o foco da criança não se perca em meio a letra da música, mas permaneça atenta às imagens.

Além disso, a música dialoga muito bem com as cenas do filme-anúncio, quase que como se ela traduzisse a canção em imagem, pois os animais estão do lado de fora da lanchonete (wherever you go) esperando as crianças que possam levá-los para casa (I will be right here waiting for you). A cena descrita pode ser conferida nas figuras 2 e 3.

9 "Onde quer que você vá, o que quer que você faça, eu estarei bem aqui esperando por você" (tradução nossa). 
Figura 2: Abertura do vídeo publicitário

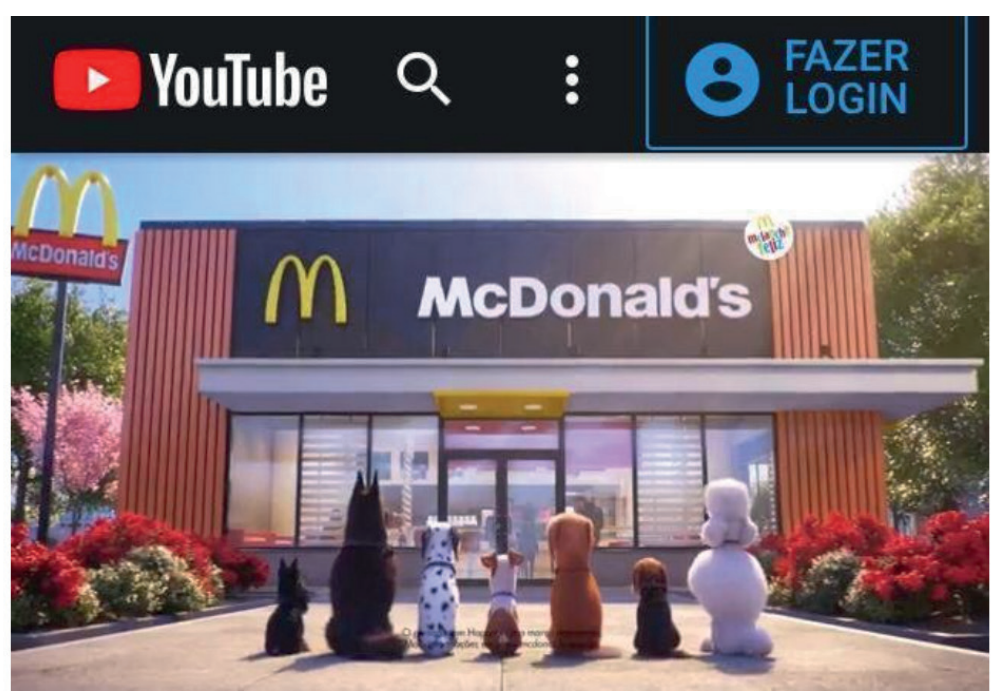

Fonte: Canal Youtube McDonald's Brasil (2019)

Figura 3: Quem sempre espera por você?

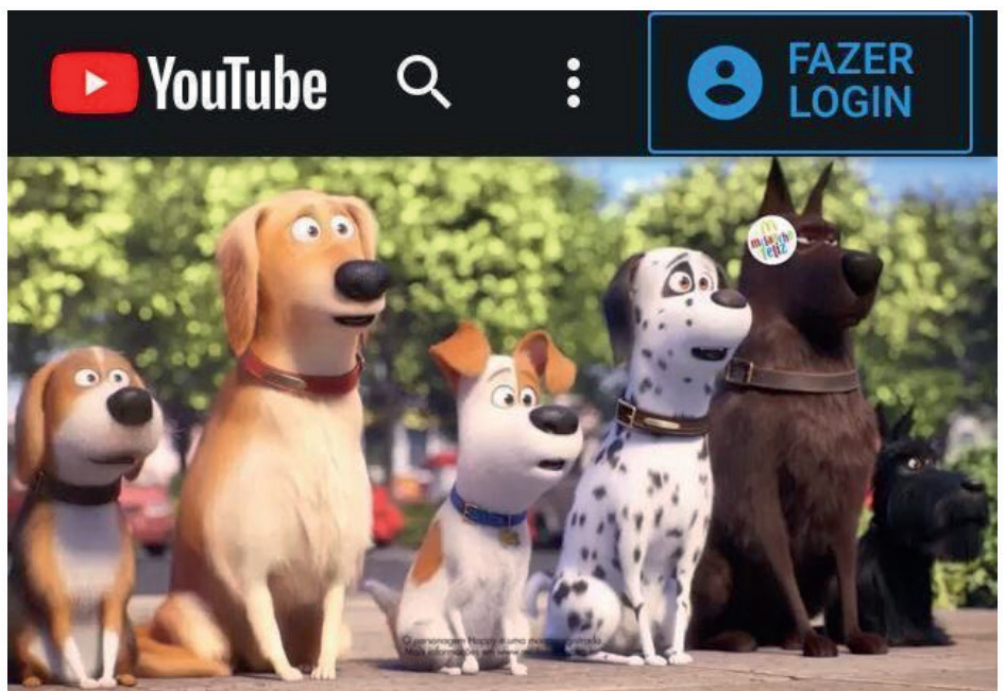

Fonte: Canal Youtube McDonald's Brasil (2019)

Na primeira cena, os cães esperam seus donos que estão dentro da lanchonete McDonald's, dois segundos após a abertura do vídeo, a primeira família, cuja filha carrega uma caixa com slogan do McDonald's, sai da filial da lanchonete. A cena não conta com textos verbais, contudo, as condições de produção de discurso e a memória discursiva, nelas inscritas, remetem ao espectador o serviço mais famoso da rede: o McLanche feliz. A menina carrega uma caixinha do McLanche Feliz e fica feliz e surpresa quando vê o seu cãozinho na porta da lanchonete. A cena descrita pode ser conferida nas figuras 4 e 5 : 
Figura 4: Menina com caixa do McLanche Feliz

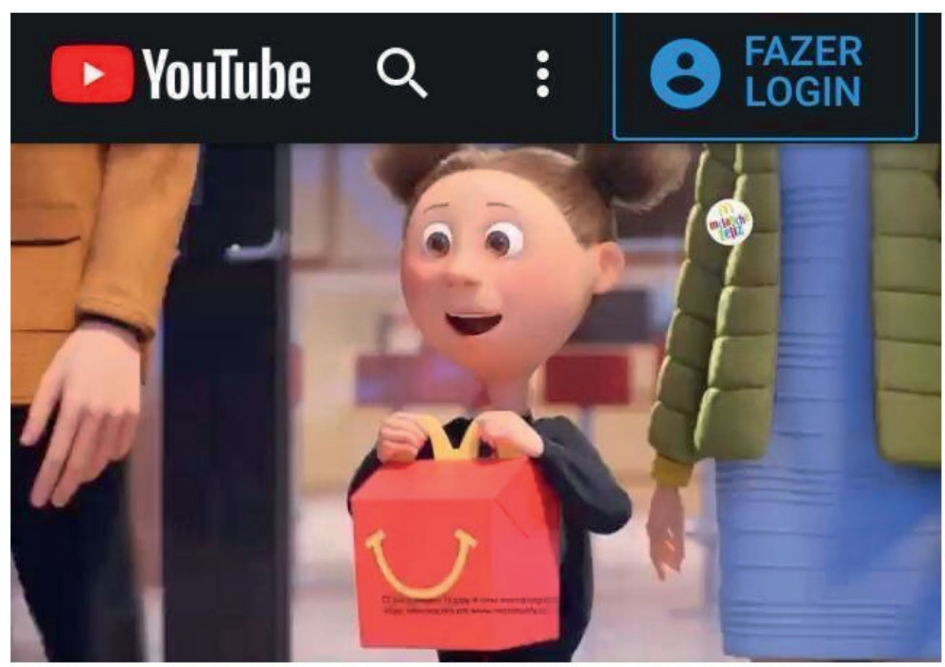

Fonte: Canal Youtube McDonald's Brasil (2019)

Figura 5: Menina com seu pet

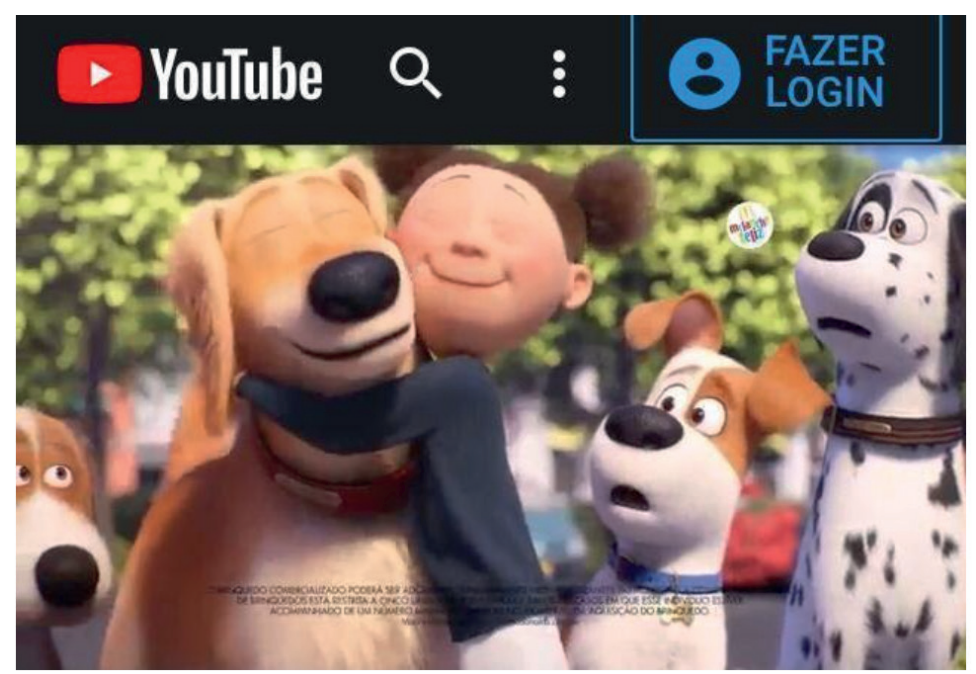

Fonte: Canal Youtube McDonald's Brasil (2019)

O cãozinho Max, personagem principal da animação, espera impaciente seus tutores, essa ansiedade é expressada com a fala "Ah! Espero que eles saiam logo..." e fica muito feliz quando o casal Chuck e Katie aparecem na porta com o pequeno Liam - “Opa! Vocês voltaram!”. Katie carrega nas mãos uma sacolinha vermelha com a logomarca amarela da rede. Desta vez quem carrega o lanche é a mãe e não a criança, considerando que Liam é um bebê.

Segundo Orlandi (2000, p.30-36) as condições de produção, que constituem os discursos, funcionam de acordo com certos fatores: 1) relação de sentidos - aqui compreendemos que não há discurso que não se relaciona com outros. Um discurso aponta para outros que o sustentam e também para dizeres futuros, assim não há começo absoluto, nem um final para o discurso; 2) mecanismo de antecipação - trata da capacidade que temos de nos colocarmos no lugar do outro, do nosso 
interlocutor. Nós podemos antecipar o sentido que as palavras podem produzir e assim, escolhemos um modo ou outro de dizer, segundo o efeito que pensamos ser possível produzir no nosso ouvinte; 3) relação de forças - “o lugar a partir do qual fala o sujeito é constitutivo do que ele diz”. Assim quando falamos a partir do lugar de professor, nossas palavras significam diferente do que quando falamos do lugar do aluno, do diretor, etc.

Figura 6: Família principal do filme-anúncio

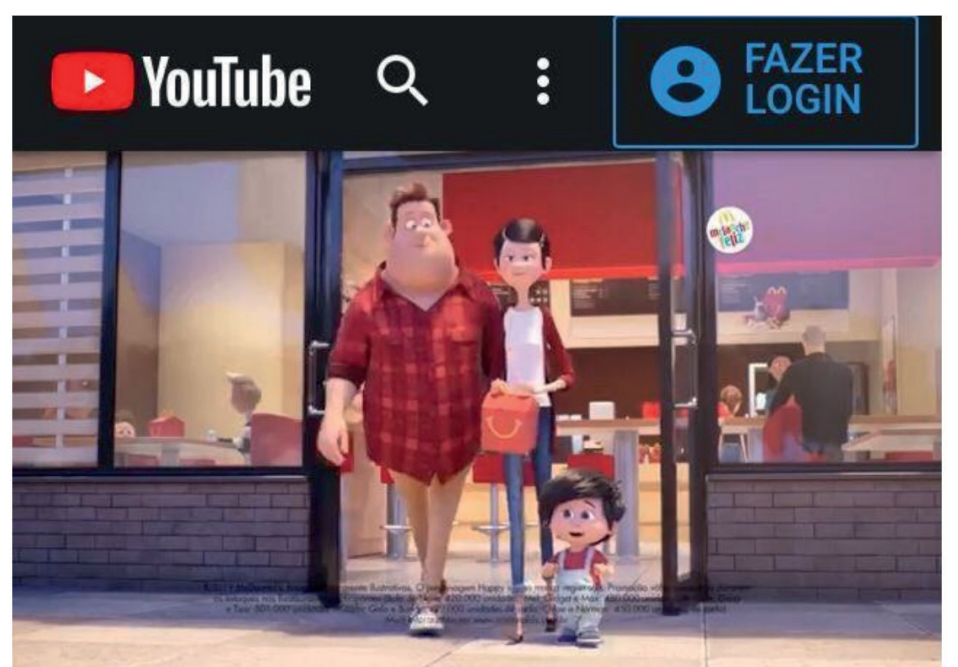

Fonte: Canal Youtube McDonald's Brasil (2019)

Figura 7: Bebê Liam e seu pet Max

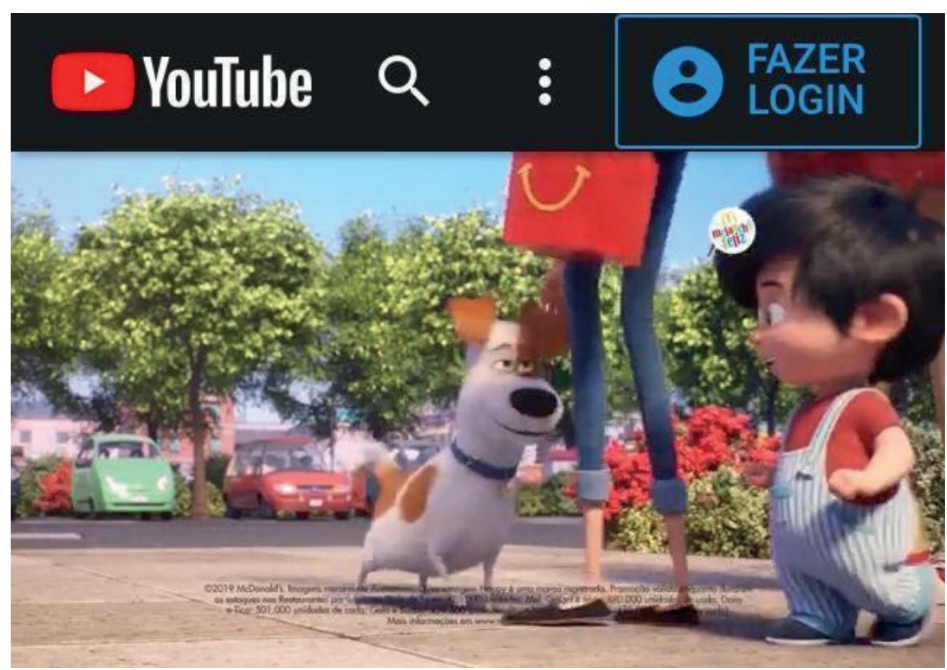

Fonte: Canal Youtube McDonald's Brasil (2019)

A imagem de Katie carregando um McLanche Feliz para um Liam confere voz para a mulher a partir do lugar de mãe que sabe o que é melhor para seu filho. Essa cena, além de trazer a força da autoridade da mãe ainda insere a força de outros ditos, de outras falas que já foram escutadas pela criança nas mais diversas situações e que reforçam a sabedoria da mãe nas escolhas que faz para ela, criança. 
Por outro lado, esse discurso também se dirige aos pais, mais especificamente à mãe, e lhe seduz ao lhe conferir voz e autoridade para recomendar o produto do anunciante. $\mathrm{O}$ olhar amistoso que o cãozinho dirige ao bebê, mostra claramente que ele, agora, aceita o novo membro da família. O McLanche Feliz trouxe tranquilidade e felicidade para todos os membros da família.

O filme publicitário encerra apresentando as imagens de todos os brindes, dez miniaturas dos personagens principais da animação Pets 2, da promoção Quem sempre espera por você? e a imagem dos produtos que compõem o McLanche Feliz. $\mathrm{O}$ vídeo conta com um recurso que a $\mathrm{AD}$ concebe como memória discursiva. De acordo com Pêcheux (1999, p. 99), a memória discursiva é caracterizada como "aquilo que, face a um texto que surge como acontecimento a ler, vem reestabelecer os 'implícitos' (quer dizer, mais tecnicamente, os pré-construídos, elementos citados e relatados, discursos-transversos, etc.) de que sua leitura necessita”. As crianças que assistiram ao filme Pets 2 associam a história e os personagens ao McLanche Feliz, passam a desejar comer o lanche e ganhar os brinquedos. Observa-se que não fizeram brinquedos dos personagens humanos, somente dos animais - os cãezinhos, símbolos de alegria, companhia e fidelidade em nossa sociedade.

Figura 8: Brindes da campanha
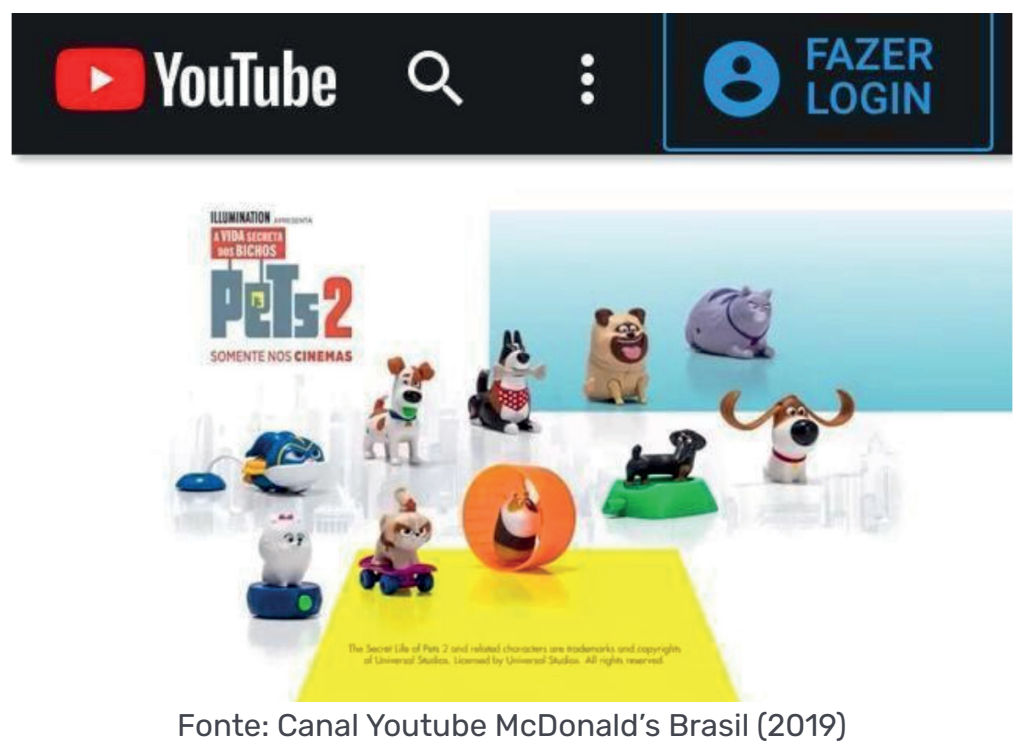

Fonte: Canal Youtube McDonald's Brasil (2019) 
Figura 9: Itens que compõem o McLanche Feliz

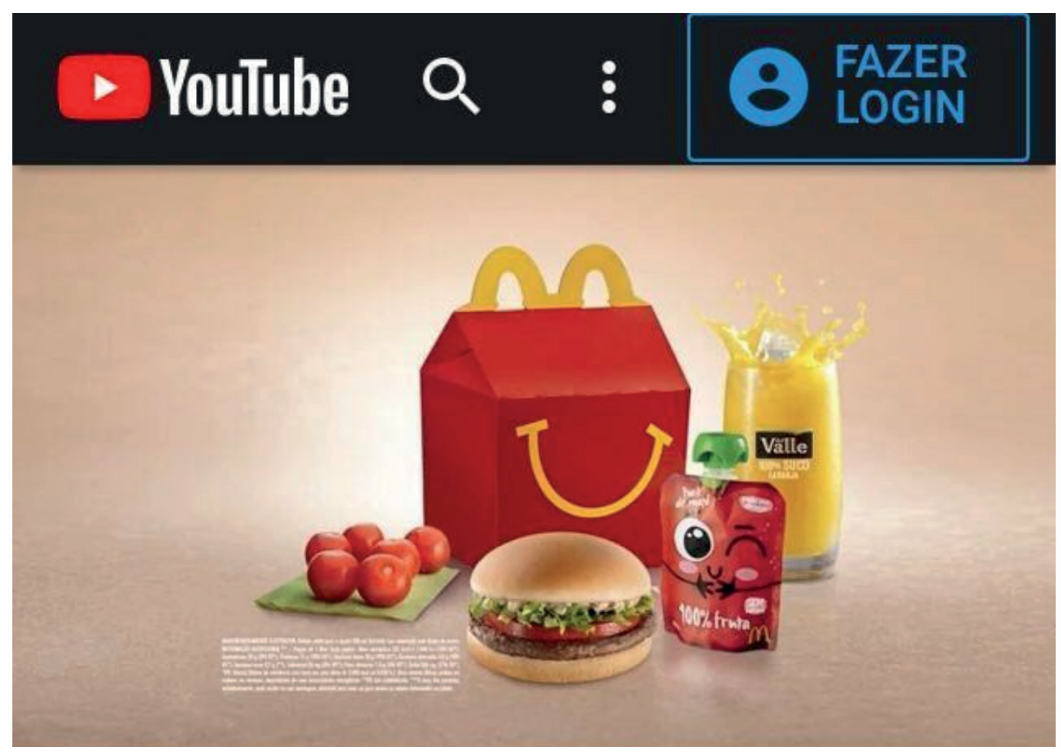

Fonte: Canal Youtube McDonald's Brasil (2019)

De acordo com Pêcheux (1997a, p. 82), “o termo discurso implica que não se trata necessariamente de transmissão de informação entre A e B, mas, de modo mais geral, de um "efeito de sentidos entre os pontos A e B". Dito de outro modo, o discurso não pode ser produzido de forma isolada, pois depende de uma interlocução enunciativa. Isto posto, entende-se que o discurso construído ao longo da campanha tem caráter de autopromoção, haja vista que os bichos, como todo pet, estão esperando seus tutores para levá-los para casa. Entretanto, para isso é preciso ir até uma filial da rede McDonald's.

Ainda para o filósofo, é a ideologia que faz com que as palavras não sejam apenas palavras, mas mudem de sentido de acordo com aqueles que as empregam. Sobre isso o autor afirma que: "As palavras, expressões, proposições, mudam de sentido segundo as posições sustentadas por aqueles que as empregam, o que quer dizer que elas adquirem seu sentido em referência a essas posições, isto é, em referência às posições ideológicas” (PÊCHEUX, 1997b, p. 160). Portanto, a ideologia impregnada na presente campanha age de forma sutil, pois ao utilizar animais domésticos como protagonistas da propaganda e atrelá-los ao título Quem sempre espera por você?, faz com que o público alvo não questione sobre ela, isto é, não pense muito antes de associar a fidelidade aos cãezinhos.

No momento em que a criança aceita o discurso da publicidade ela, enquanto sujeito, passa a constituir-se pelo discurso publicitário, desta forma se o anunciante atribui ao seu consumidor a imagem de um tutor de um dos pets o consumidor atribui a si próprio a representação de fazer parte da animação ao adquirir o McLanche Feliz. 


\title{
4 Considerações finais
}

Ao indagar "quem sempre espera por você?" o enunciador propõe através da memória discursiva que os pets estão sempre à espera de seus tutores. Na campanha em questão, os cãezinhos são associados ao McLanche Feliz, através da narrativa da animação publicitária e também dos brindes ofertados junto com os produtos alimentícios.

A rede é impedida legalmente de impor a compra do lanche para aquisição dos brinquedos, por isso é possível adquiri-los de forma independente, porém o lanche (com o brinde) custa uma média de $\mathrm{R} \$ 17,00$ (dezessete reais), enquanto o brinquedo avulso custa $\mathrm{R} \$ 13,00$ (treze reais). A baixa diferença de preços estimula os pais a comprar o lanche completo e assim a Rede McDonald's pode fidelizar a criança como cliente por muitos anos.

Observa-se ainda que apesar de ter a criança como alvo principal, os discursos publicitários apresentam também argumentos, linguísticos e imagéticos, destinados ao adulto que paga mesada ou finaliza a compra da criança.

Esperamos que essa reflexão possa contribuir para abrir novos espaços para que outros estudiosos interessados no tema possam aproveitar desta produção para desenvolver diferentes análises a respeito do material publicitário destinado ao público infantil.

\section{WHO IS WAITING FOR YOU? A MCDONALD'S ADVERTISING FOR THE HAPPY MEAL}

\begin{abstract}
Based on the theoretical device of Discourse Analysis, French Line, It is analyzing the advertising discourses disclosed in the Happy Meal campaign, a special snack for kids by the fast-foods chain McDonald's. This paper's corpus was collected on the McDonald's Brasil, by YouTube channel. It is a video made for the 2019's campaign entitled Who is always waiting for you? which protagonists are from the movie The secret life of Pets 2, produced by Universal Studios. The enunciator proposes, through the discursive memory, that the pets are always waiting for their tutors and the puppies are associated through the gifts to the Happy Meal. This facilitates the kids' adherence to the presented discourse and a possible product consumption and loyalty.
\end{abstract}

Keywords: McDonald's; Children’s advertising; Discourse Analysis; Happy Meal.

\section{Referências}

CARTOON, N. Kids Expert 2007 - Pesquisa. Disponível em: https://

criancaeconsumo.org.br/wp-content/uploads/2014/02/135430796-Kids-ExpertCartoon-Network.pdf. Acesso em: 03 dez. 2020.

GREGOLIN, M. do R. Olhares oblíquos sobre o sentido no discurso. In: GREGOLIN, M. do R.; BARONAS, R. (org.). Análise do discurso: as materialidades do sentido. São Carlos: Claraluz, 2001. 
LEITTE, S. In: MUNDO DO MARKETING. Kids Expert - Pesquisa. Quem é o consumidor infantil. Disponível em: http://www.mundodomarketing.com.br/ mais-mundo-domarketing/ estudos/12/quem-e-o-consumidor-infantil-.html. Acesso em: 11 nov. 2013.

LINN, S. Crianças do consumo: a infância roubada. São Paulo: Instituto Alana, 2006.

MALDIDIER, Denise. A inquietação do discurso: (re)ler Michel Pêcheux hoje. Campinas:Pontes, 2003

MCDONALD'S BRASIL. Mclanche feliz pets - a vida secreta dos bichos 2. 2019. Disponível em: https://www.youtube.com/watch?v=ZkxIVFaTD1g. Acesso em: 08 jan. 2020.

MUNDO DO MARKETING. TNS Global/InterScience Quem é o consumidor infantil. Disponível em: http://www.mundodomarketing.com.br/mais-mundo-domarketing/estudos/12/quem-e-o-consumidor-infantil-.html. Acesso em: 25 nov. 2013.

MUNDO DO MARKETING. Disponível em: https://www.mundodomarketing. com.br/. Acesso em: 25 nov. 2019.

NICOLINO, L. Mais que influenciador, consumidor infantil é decisor. Disponível em: http://www.mundodomarketing.com.br/reportagens/pesquisa/25721/maisque-influenciadorconsumidor-infantil-e-decisor.html. Acesso em: 11 out. 2013.

PÊCHEUX, M. Análise automática do discurso (AAD-69). In: GADET, F.; HAK, T. (org.). Por uma análise automática do discurso: uma introdução à obra de Michel Pêcheux. Campinas: Ed. da Unicamp, 1997a.

PÊCHEUX, M. Semântica e discurso: uma crítica à afirmação do óbvio. Campinas: Ed. da Unicamp, 1997b.

PÊCHEUX, M. Papel da memória. In: ACHARD, P. et al. Papel da memória. Campinas: Pontes, 1999.

PÊCHEUX, M. Análise de Discurso: Michel Pêcheux. Textos escolhidos por Eni Puccinelli Orlandi. Pontes Editora: Campinas - SP, 2015

VELOSO, A. R. et al. Marketing e o mercado infantil. São Paulo: Cengage Lerning, 2012.

Recebido em 20 de outubro/2020 Aprovado em 22 de dezembro/2020 